\title{
SOME PERSPECTIVES ON THE TRANSFER OF CELL-MEDIATED IMMUNITY BY IMMUNE-RNA
}

\author{
Sheldon DRAY \& Donald P. BRAUN \\ Department of Microbiology and Immunology, University of Illinois at the Medical Center 835 S. \\ Wolcott, Chicago, IL 60612
}

(Received December 1, 1978)

\section{Summary}

Ribonucleic acid extracts of lymphoid cells from immune hosts were used to transfer in vivo and in vitro cell-mediated immune reactivity to a variety of antigens. The in vivo immune responses transferred by RNA included the delayed cutaneous hypersensitivity reaction to fungal and chemically-defined antigens and the tumor-rejection reaction to guinea pig hepatoma antigens. The in vitro immune responses transferred by RNA included macrophage migration inhibition by fungal, chemicallydefined, and tumor antigens. The transfer activity of RNA preparations was contained in the $8 \mathrm{~s}$ to $18 \mathrm{~s}$ species of RNA and was sensitive to RNase but not to DNase or trypsin. Antigen was not detectable in the RNA preparations and appeared to have no role in the transfer activity. Syngeneic, allogeneic, or xenogeneic sources of RNA could transfer immune reactivity. In each system tested, the transfer of cell-mediated reactivity by RNA was specific for the antigen used to sensitize the RNA donor. The potential use of RNA-mediated transfer of immunity is discussed.

\section{Introduction}

It is recognized that immunological reactions classified as cell-mediated can be transferred to a suitable host by lymphoid cells but not by serum antibodies. The type of cells mediating the transfer are thymus-derived lymphocytes ( $\mathrm{T}$ cells) that demonstrate specific reactivity to the sensitizing antigen and appear to be an obligatory component in the rejection of histoincompatible grafts, the delayed-type hypersensitivity (DTH) skin test reaction, the graftvs-host reaction, the production of many lymphokines, and the rejection of many types of tumors.

Since 1967 , our laboratory has studied the transfer of cellular immunity with RNA extracted from the lymphoid tissues of immune donors. The active principal in these extracts, usually referred to as "immune-RNA" (I-RNA) is obtained by the hot/cold phenol method of SCHERRER and DARNELL ${ }^{1}$ with some modifications of our own ${ }^{2,3}$. Our studies encompass human, monkey, guinea pig, and murine systems and include both in vitro and in vivo transfer methodology. We have observed that the transfer of cellular immunity by I-RNA is specific for the antigen used to sensitize the RNA donor and is not restricted by species barriers. Thus, cellular immunity to a wide variety of antigens has been transferred in xenogeneic, allogeneic, and syngeneic model systems (Fig. 1). The purpose of this article is to relate our experience in transferring cellular immunity with I-RNA, to consider the problems we have encountered, and to explore the prospects for further application of I-RNA. 


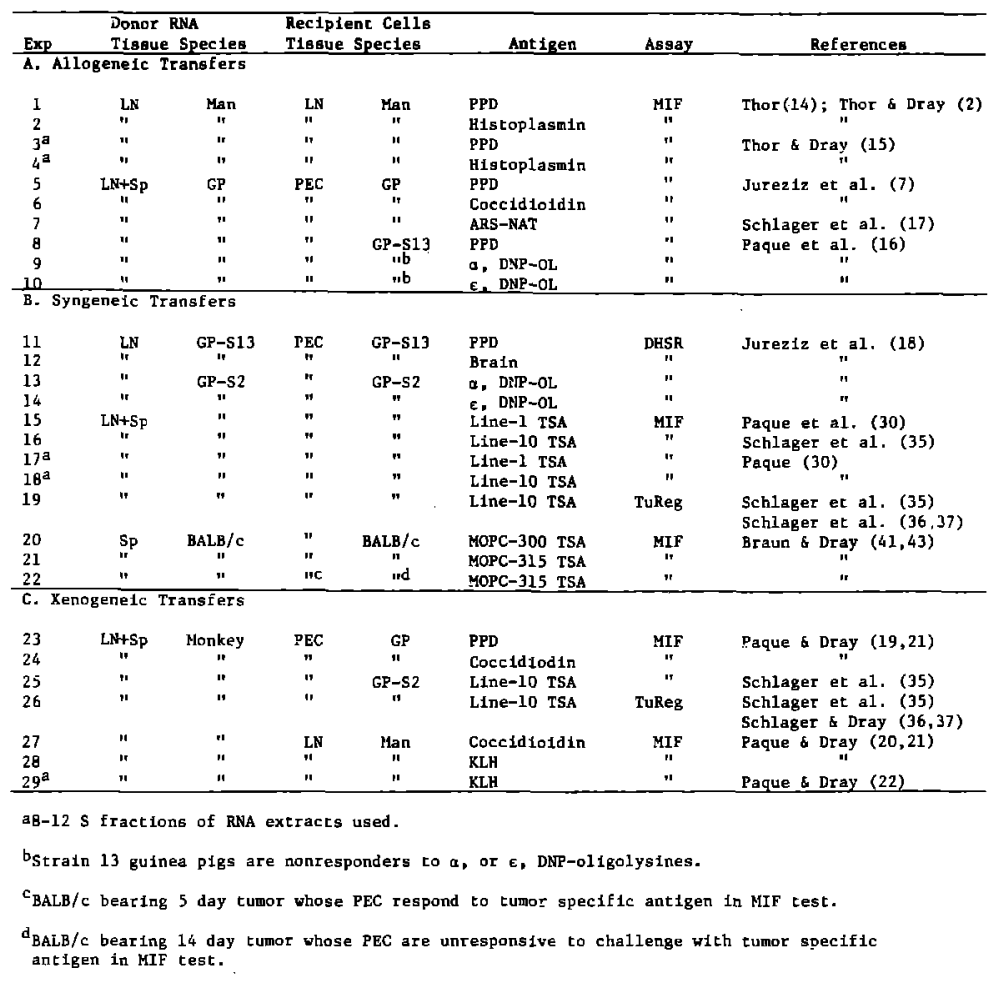

Fig. 1. Transfer of Cellular Immunity with Immune RNA extracts

\section{Materials and Methods}

All of the methods which we have employed in our studies have been described in detail in the review by PAQUE ${ }^{4}$, and therefore, will not be dealt with in depth here. A brief description of the essential technology involved in I-RNA transfer is presented.

Assays.

To assess I-RNA mediated transfer of cellular immunity by lymphokine production, we have relied upon the in vitro macrophage migration inhibition assay in which antigen-sensitized $\mathbf{T}$ cells, when stimulated with the sensitizing antigen, elaborate a proteinaceous substance, migration inhibition factor (MIF), which inhibits the migration of lymphoid cells in tissue culture (Fig. 2). We have employed two distinct MIF assays in our studies, one relying on the migration of cells from capillary tubes set into Sykes-Moore chambers and the other relying on the migration of cells from a microdroplet of cells suspended in agarose $e^{5,6}$. Lymphoid cell populations consisting of spleen, lymph node, and/or peritoneal exudate cells have been used in both a direct and an indirect MIF assay.

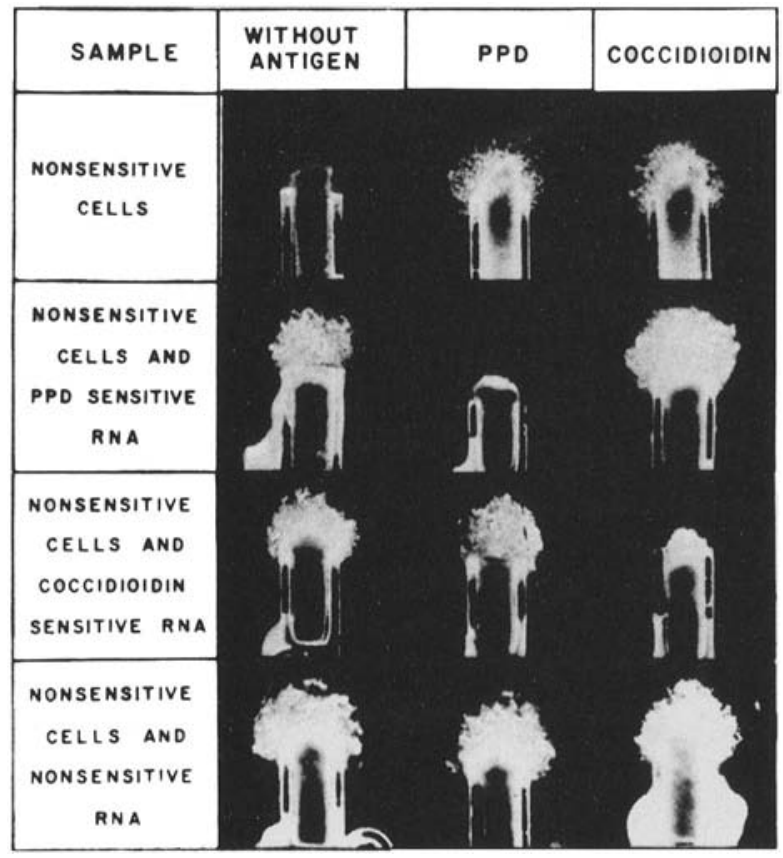

Fig. 2. Typical examples of the migration of nonsensitive guinea pig p.e. cells from capillary tubes, in Sykes-Moors chambers containing no antigen, PPD, or coccidioidin, before and after the cells were incubated with RNA extracts of lymph nodes and spleen from nonsensitive, PPD sensitive, or coccidioidin-sensitive guinea pigs. (From Jureziz et $a .^{7}$ Reproduced by permission of the Journal of Immunology.) 
The direct MIF assay is performed by culturing lymphoid cells in the presence or absence of the specific sensitizing antigen for 24-48 hr. Upon completion of the incubation period, the areas of cellular migration are measured and a comparison between the migration area of inhibited cells stimulated with antigen and control cells not stimulated with antigen is expressed quantitatively by a mean migration index ${ }^{7}$. This permits a determination of the $95 \%$ confidence interval for the significance of the variation in migration areas of inhibited and noninhibited cell cultures. A statistical study of the MIF assay by BERgSTRAND and KALLEN ${ }^{8}$ has established a criteria for a positive response in this assay so that we consider Mean migration indices (MI) of $60 \%$ or less as clearly positive and Mean migration indices of $80 \%$ or greater as essentially negative.

The indirect MIF assay takes advantage of the fact that the MIF lymphokine, when present in tissue culture fluids, can be detected with nonsensitive guinea pig peritoneal exudate cells $\mathrm{PEC}^{9,10}$. This technique is applied primarily to assess MIF production from human lymphoid cells since a suitably migrating population of human cells is often difficult to obtain. Nonsensitive human lymphoid cells are treated with I-RNA and subsequently cultured for $24-48 \mathrm{hr}$ in the presence or absence of antigen. At the end of the incubation period, the culture supernatants are harvested and tested for the presence of MIF with nonsensitive guinea pig PEC. The calculation of a mean migration index is made in the same manner used for the direct MIF assay. The MIF assay has proven to be extremely useful for our purposes since elicitation of MIF is antigenically specific, activity reflected in the assay correlates well with the in vivo delayed type hypersensitivity skin test, and experiments can be performed with human lymphoid tissues (by the indirect MIF assay) without subjecting donors to untoward experimental risks.

To a lesser extent, we have relied upon in vivo tests to study the transfer of cellular immunity with I-RNA since the number of RNA-treated cells required for these tests is usually large and the biological variability inherent in the recipients of RNA-treated cells is difficult to control. The in vivo tests which we have used to demonstrate the transfer of cellular immunity with I-RNA include delayed type hypersensitivity (DTH) skin tests and tumor regression, both phenomena usually being dependent upon the presence of specifically sensitized T cells. Delayed type hypersensitivity skin test reactions are due to the influx of mononuclear leukocytes, particularly $\mathrm{T}$ cells and macrophages, into the site of antigen injection $24-48 \mathrm{hr}$ after antigenic challenge. A positive test is characterized by the elicitation of an indurated lesion of at least $5 \mathrm{~mm}$ diameter with or without accompanying erythema. The determination of tumor regression for progressively growing solid tumors is accomplished by comparing the diameters of tumor papules at multiple intervals prior to and following the onset of therapy.

\section{Antigens.}

Our studies have employed a wide variety of antigens to sensitize I-RNA donors to a state of cellular immunity. The initial studies relied on relatively crude fungal or bacterial antigens such as Purified Protein Derivative of Mycobacteria (PPD), Keyhole Limpet Hemocyanin (KLH), histoplasmin, and coccidioidin which are all known to elicit cellular immunity in the immunized host. With these antigens, specific immunological reactivity could be transferred to nonsensitive cells but some of these antigens exert mitogenic effects on lymphoid cells that could lead to ambiguous results in the MIF assay. For these reasons, our later studies relied in part on antigens of known chemical structure which were demonstrably not mitogenic. One such antigen is a low MW (486) molecule, mono-(p-azobenzenearsonate)-N-chloroacetyl-Ltyrosine, (ARS-NAT). Guinea pigs immunized with ARS-NAT emulsified in Freund's complete adjuvant develop DTH and MIF reactivity to this antigen ${ }^{11}$. We have also used, as chemically defined antigens, a series of DNPoligolysine conjugates. Both alpha-DNPoligolysines and epsilon-DNP-oligolysines were used to immunize RNA donors who manifested DTH and MIF reactivity upon antigenic challenge. The DNP-oligolysines proved particularly suitable for certain RNA transfer experiments since responsiveness to these antigens in the guinea pig is known to be controlled by an autosomal dominant immune response gene which is lacking in one strain of inbred guinea 
pigs. We have also employed tumor antigens in our studies utilizing I-RNA to transfer cellular immunity. Typically, the tumor antigens were extracted from tumor cells with $3 \mathrm{M} \mathrm{KCl}$ by the methods of ReISFELD and KAHAN ${ }^{12}$ and MELTZER et al. $^{13}$. The extraction procedure provides antigens which are soluble by the criteria of high speed centrifugation, free of toxic particulates with mitogenic activity, and capable of eliciting DTH and MIF reactivity upon challenge of immune donors or their cells. Both a guinea pig hepatoma tumor system and a murine plasmacytoma system were studied.

Extraction of I-RNA, incubation with lymphoid cells, and Sucrose density gradient centrifugation. The method used to extract I-RNA from the lymphoid tissues of immune donors is patterned after the procedure developed by SCHERRER and DARNELL $^{1}$ with modifications by THOR and DrAY ${ }^{2}$ and PAQue and DraY ${ }^{3}$. This procedure is generally referred to as the hot/cold phenol method and is dependent upon the ability of hot phenol to rapidly denature chromosomal proteins. Under the conditions of the procedure, most of the DNA (greater than 95\%) remains insoluble and the denatured proteins are precipitated with associated DNA. Briefly, freshly prepared or frozen tissues are homogenized in a solution of cold phenol and sodium acetate buffer ( $\mathrm{pH} \mathrm{5.1)}$ at $4{ }^{\circ} \mathrm{C}$ for $15 \mathrm{~min}$. At the end of the homogenization period, an equal volume of sodium acetate buffer is added to the homogenate which is then heated to $55^{\circ} \mathrm{C}$ and rapidly cooled to $4^{\circ} \mathrm{C}, 3$ to 4 times. Following the last extraction, the aqueous phase containing RNA is precipitated overnight with chilled $95 \%$ ethanol 2 to 3 times and stored at $-20^{\circ} \mathrm{C}$ until use. Lymphoid cells to be treated with RNA are washed in isotonic medium and resuspended in either Hanks' Balanced Salt Solution (HBSS) incorporating $0.3 \mathrm{~m}$ RNase-free sucrose and 2 units $/ \mathrm{ml}$ heparin, or serum-free RPMI medium (0.5-2.0 ml). RNA ( $200 \mu \mathrm{g}$ to $2 \mathrm{mg}$ ) is added to the cell suspension $\left(2 \times 10^{6}\right.$ to $1 \times 10^{9}$ cells) which is then incubated on a shaking water bath for $15-30 \mathrm{~min}$ at $37^{\circ} \mathrm{C}$. Upon completion of the incubation period, the cells are washed in tissue culture medium prior to initiating the in vitro or in vivo assessment of RNA transfer. The biochemical integrity of the I-RNA obtained by the hot/cold phenol extraction procedure is evaluated by sucrose density gradient centrifugation. Approximately $125 \mu \mathrm{g}$ of RNA dissolved in $0.11 \mathrm{M}$ sodium acetate buffer is layered onto a linear, $5-40 \%$ sucrose gradient which is then centrifuged at $28,000 \mathrm{rpm}$ at $4{ }^{\circ} \mathrm{C}$ for $18 \mathrm{hr}$. After centrifugation, the sucrose gradients are fractionated with an ISCO Model D sucrose density fractionator and optically analyzed at $254 \mathrm{~m} \mu$ with an ISCO Model UA-2 analyzer.

\section{Results}

The ability to transfer immunological responsiveness to a recipient host with allogeneic or xenogeneic lymphoid cells is restricted by host reactions to histocompatibility antigens of the transferred cells or by graft-vs-host reactions of the transferred cells to host tissue antigens. Moreover, host immunological responses are restricted by genetic and/or immunologic control mechanisms. The employment of I-RNA to transfer cell-mediated immunity is aimed at circumventing the complications engendered in recipients of incompatible cells and at eliciting phenotypic activity in lymphoid cells whose activity would otherwise be restricted genetically or immunologically.

Transfer of cellular immunity with allogeneic I-RNA.

The investigations in our laboratory began with allogeneic transfers in $\operatorname{man}^{2,14,15}$. Allogeneic I-RNA was prepared from lymph nodes of humans hypersensitive to PPD or histoplasmin and used to transfer MIF reactivity to nonsensitive human lymph node cells. The targets of transfer were $72 \mathrm{hr}$ cultured lymph node cells whose in vitro migratory activity was sufficient to allow assessment of MIF production. Single lymph node cell suspensions from a human donor who had negative skin test reactions to both PPD and histoplasmin and whose cells were not inhibited in their migration by either antigen were incubated with $400-600 \mu \mathrm{g}$ of RNA prepared from lymph nodes of a patient exhibiting strong skin test and MIF reactivity to both antigens. In this example, dual transfer of PPD and histoplasmin reactivity was obtained as demonstrated by the subsequent inhibition of migration of RNA-treated cells in the presence of purified protein derivative (PPD) $(\mathrm{MI}=18 \%)$ 
or histoplasmin $(\mathrm{MI}=22 \%)$. Antigenic specificity of transfer was shown utilizing different preparations of RNA from patients exhibiting either strong reactivity to histoplasmin or to PPD but not both. With the histoplasmin-IRNA preparation, histoplasmin sensitivity was transferred $(\mathrm{MI}=14 \%)$ to nonsensitive cells but PPD sensitivity was not $(\mathrm{MI}=102 \%)$; while with the PPD-I-RNA preparation, PPD sensitivity was transferred ( $\mathrm{MI}=21 \%$ ) but histoplasmin sensitivity was not $(\mathrm{MI}=101 \%)$. RNAtreated cells that were not stimulated with antigen were not inhibited in their migration.

Allogeneic sources of I-RNA have also been prepared in guinea pigs and used to transfer MIF reactivity to $\mathrm{PPD}^{7,16}$, coccidioidin ${ }^{7}$, alpha DNP-oligolysines ${ }^{16}$, epsilon DNP-oligolysines ${ }^{16}$ and ARS-NAT ${ }^{17}$. RNA from random-bred guinea pigs hyperimmunized to BCG or coccidioidin was used to transfer MIF reactivity for these antigens to PEC from random bred nonsensitive albino guinea pigs. Neither the antigen alone nor RNA extracts from unimmunized guinea pigs were able to convert these cells to a state of sensitivity ruling out a mitogenic effect for these antigens on guinea pig PEC.

Allogeneic I-RNA was used by PAQue et al. to transfer MIF reactivity for the chemically defined antigens alpha DNP-oligolysines and epsilon-DNP-oligolysines to PEC from genetic nonresponder Strain-13 guinea pigs. Strain-2 guinea pigs which are genetically capable of strong reactivity to DNP-oligolysines served as donors of I-RNA which was used to treat Strain-13 guinea pig PEC. RNA-treated PEC were inhibited in their migration by the corresponding antigen used to sensitize the RNA donor. These experiments demonstrated the exquisite specificity of cell-mediated immune reactions which are reflected in the reactions transferred by 1 -RNA.

RNA from random bred guinea pigs was employed by SCHLAGER et al. to transfer MIF reactivity to the ARS-NAT antigen. Specific inhibition of migration of nonsensitive guinea pig PEC was observed following treatment with ARS-NAT-I-RNA in the presence of ARSNAT while no inhibition occurred with RNA alone or by incubation of the RNA-treated cells with unrelated antigens. The use of ARS-NAT as antigen for the transfer of cell-mediated immunity by I-RNA was significant since most of the antigens used in previous experiments were of bacterial or fungal origin, chemically undefined, and usually possessive of mitogenic activity. ARS-NAT does not suffer from these problems and therefore, lent itself readily to an evaluation of the dependancy of I-RNA on contaminating antigen (see below).

The ability of allogeneic I-RNA extracts from BCG-immune guinea pigs to transfer DTH skin test reactivity was also demonstrated ${ }^{18}$. Random bred albino guinea pigs injected intradermally with a $0.1 \mathrm{ml}$ suspension containing $1 \times 10^{7}$ RNA-treated PEC and $10 \mu \mathrm{g} / \mathrm{ml}$ PPD demonstrated indurated skin reactions (6$14 \mathrm{~mm}$ ) which were greater than those observed in the same animals at sites injected with untreated PEC+ PPD (1-5 mm) or at sites injected with RNA-treated PEC without PPD (2-5 mm).

\section{Transfer of cellular immunity with xenogeneic I-RNA.}

Circumvention of species barriers in transferring cellular reactivity may be accomplished with I-RNA from immune lymphoid cells. RNA from the spleens and lymph nodes of Rhesus monkeys sensitized to PPD, KLH, or coccidioidin was able to transfer antigen specific reactivity to guinea pig PEC and human peripheral blood lymphocytes ${ }^{19-22}$. Assessment of transfer activity to human peripheral blood lymphocytes was accomplished by the indirect MIF assay. Human nonsensitive peripheral blood lymphocytes were incubated with RNA extracts of lymphoid tissue from Rhesus monkeys with skin test sensitivity to KLH, PPD, and/or coccidioidin. In the presence of the corresponding antigen, RNA-treated human leukocytes specifically elaborated the MIF lymphokine whose presence in culture supernatants was detected with nonsensitive guinea pig PEC. Liver RNA extracts from sensitized Rhesus monkeys or RNA extracts from lymphoid tissues of nonsensitive monkeys, in the presence of antigen, failed to induce MIF production in human leukocytes. Transfer of PPD and coccidioidin sensitivity to nonsensitive guinea pig PEC with Rhesus monkey I-RNA was shown with the direct MIF assay. RNA-treated nonsensitive guinea pig PEC were inhibited in their migration in the presence of the specific antigen but not in the presence of an unrelated antigen, 
histoplasmin, or in the absence of antigen. The approach developed in these experiments suggested novel approaches to immunotherapy of tumors which culminated in the development of an RNA therapy model for guinea pig hepatomas employing xenogeneic sources of I-RNA (see below).

Transfer of cellular immunity with syngeneic I-RNA.

The transfer of cell-mediated immunity via syngeneic I-RNA permitted an unambiguous appraisal of the in vivo activity of RNA-treated lymphoid cells whose reactivity could not be attributed to allogeneic or xenogeneic stimulation of responder cells. The transfer of DTH skin test reactivity to PPD, brain antigen, alphaDNP-oligolysine, and epsilon DNP-oligolysine was accomplished utilizing syngeneic I-RNA ${ }^{18}$. Strain-13 guinea pigs which had not been previously skin tested were skin tested with PPD or brain antigen between 58 and 64 hrs after receiving an intraperitoneal injection of approximately $1 \times 10^{9}$ syngeneic lymph node or spleen cells that had been incubated with I-RNA from PPD-immune or brain antigenimmune donors. At the skin sites injected with PPD, the induration observed varied from $7-$ $14 \mathrm{~mm}$ with marked erythema as compared to $0-3 \mathrm{~mm}$ induration and negligible erythema at sites injected with a noncross-reacting antigen. The sites injected with brain antigen exhibited from 6-11 $\mathrm{mm}$ induration with considerable erythema. Strain-13 guinea pigs injected with PPD or brain antigen alone as controls exhibited less than $3 \mathrm{~mm}$ induration and no accompanying erythema. Strain-2 guinea pigs which are genetically capable of responding to alpha and epsilon-DNP-oligolysines were skin tested with these antigens between 58 and $68 \mathrm{hr}$ after receiving an intraperitoneal injection of syngeneic nonsensitive lymph node or spleen cells that had been incubated with RNA from immunized donors. Animals receiving lymphoid cells treated with alpha-DNP-oligolysine I-RNA exhibited indurated skin tests varying from 6-15 mm with marked erythema upon injection of the homologous antigen but only $0-2 \mathrm{~mm}$ of induration with negligible erythema upon injection of epsilon-DNP-oligolysine. This pattern of reactivity was reiterated in guinea pigs receiving lymphoid cells treated with epsilon-
DNP-oligolysine I-RNA in that significant induration was seen in sites injected with epsilonDNP-oligolysine (8-17 mm) with marked erythema while negligible induration $(0-3 \mathrm{~mm})$ and erythema was seen in sites injected with alpha-DNP-oligolysine. Attempts to elicit skin test sensitivity to these antigens with I-RNA alone (up to $2.11 \mathrm{mg} /$ guinea pig) or with nonsensitive guinea pig cells mixed with DNPoligolysines were totally unsuccessful.

\section{Characterization of I-RNA}

Part of our efforts have been devoted to characterizing the biologically active principal in our relatively crude I-RNA preparations. Analysis of the I-RNA obtained by the hot/cold phenol extraction procedure has led to several general findings in all of the systems we have tested. By sucrose density gradient centrifugation, the RNA extracts have characteristic $28 \mathrm{~s}$, $18 \mathrm{~s}$, and $4 \mathrm{~s}$ peaks. The biuret test indicates less than $3 \%$ contamination with protein. When the RNA extracts are treated with DNase or trypsin, the sucrose density gradient centrifugation patterns are essentially unaltered and the RNA extracts retain their transfer activity. However, when the RNA extracts are treated with pancreatic RNase, transfer activity is abolished and virtually all of the high molecular weight RNA species is degraded as indicated by the presence of only $4 \mathrm{~s}$ material or smaller on the sucrose gradient patterns (Fig. 3). These observations clearly illustrate that high molecular weight RNA is an essential component for transfer activity. They do not, however, rule out the possibility that minute amounts of protein are also needed for transfer activity.

The presence or absence of antigen in I-RNA is one of the central controversies inherent in the study of I-RNA-mediated transfer of immunity. This issue is germane since it raises the question of the mechanism responsible for the transfer of cellular immunity with I-RNA. Two distinct hypotheses predominate the literature on this subject. Some investigators favor a super antigen concept in which RNA condenses with antigenic determinants to form a potent immunogen that can directly sensitize lymphoid cells. These RNA-antigen complexes and their role in I-RNA mediated transfer of immune reactivity have been reviewed extensively by GOTTLIEB and SCHWARTZ ${ }^{23}$ and therefore, will not 


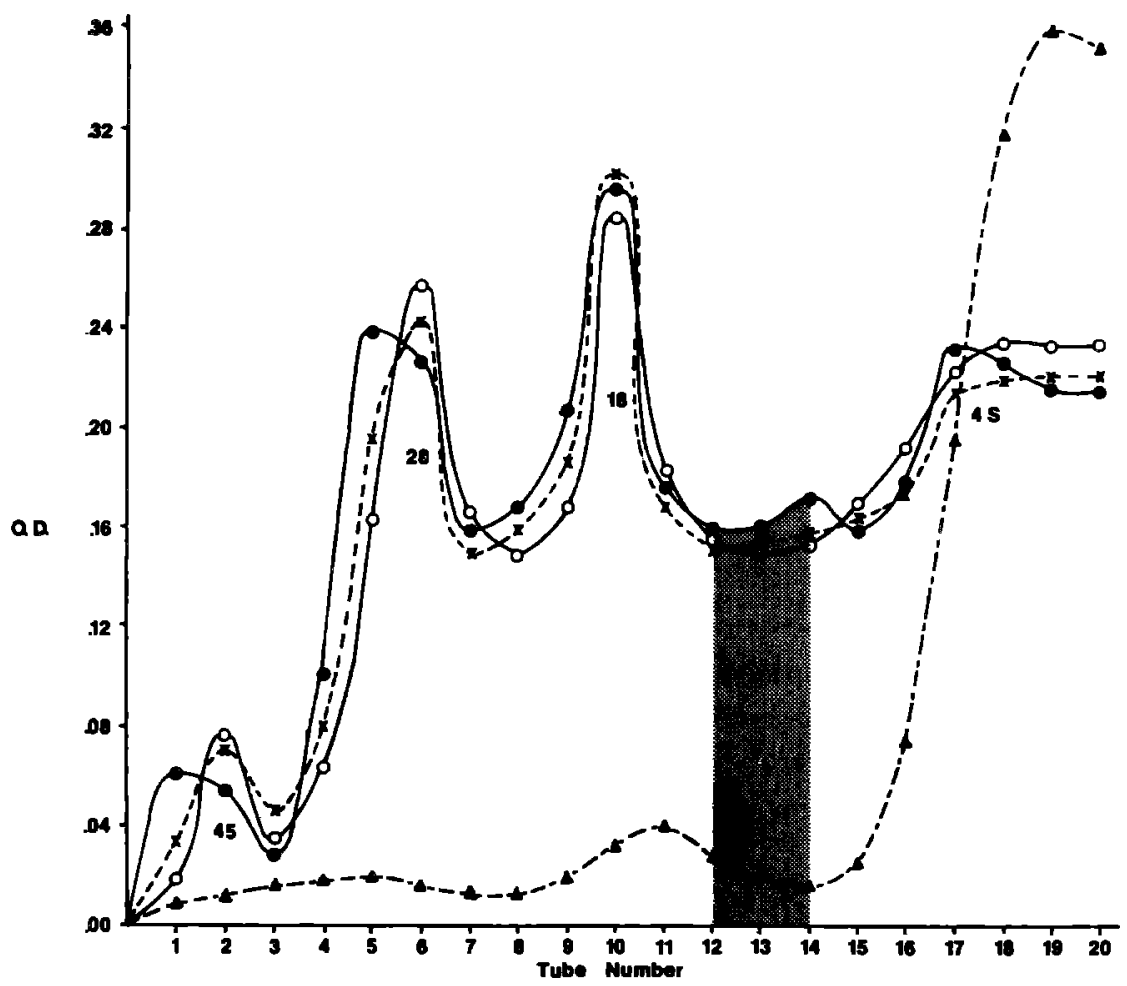

Fig. 3. Sucrose density gradient patterns of RNA species isolated as the RNA extract from PPD-sensitive RNA donor BC. Classical RNA species are represented as peaks $4 \mathrm{~S}$ (top of tube), $18 \mathrm{~S}, 28 \mathrm{~S}$, and $45 \mathrm{~S}$ (bottom of tube). Intact RNA lymph node extract, $(10)$; RNA extract after incubation with DNase, $(\mathrm{O}-\mathrm{O})$; RNA extract after incubation with trypsin, $(\times---x)$; RNA extract after incubation with RNase, $(\mathbf{\Delta}-\mathbf{A})$.

(From ThOR and DraY ${ }^{15}$ Reproduced by permission of the Annals of the New York Academy of Science)

be considered here. Another hypothesis advanced to explain the action of RNA in transferring immunity proposes an informational role for the I-RNA. Presumably, informational I-RNA would not require the presence of antigen for transfer of reactivity. In our own work, we have been unable to detect antigen contamination in our I-RNA preparations by immunological or chemical tests. For example, JuREzIz et al. ${ }^{18}$ tested the ability of I-RNA from DNPoligolysine immune guinea pigs to sensitize normal animals. Guinea pigs that received up to $2.1 \mathrm{mg}$ of I-RNA intraperitoneally, an amount of RNA 10 fold greater than the amount of material needed to convert nonsensitive lymphoid cells to a state of reactivity, did not develop positive DTH skin tests upon challenge with DNP-oligolysine. In addition, normal spleen cells that had been treated with $25 \mu \mathrm{g}$ of DNP-oligolysine were unable to transfer DTH skin test reactivity to normal guinea pigs. We have also attempted to elicit MIF from PPDsensitized guinea pig PEC with I-RNA prepared from PPD-sensitized hosts ${ }^{19}$. Whereas the sensitized PEC were inhibited in their migration by as little as $10 \mu \mathrm{g} / \mathrm{ml}$ of PPD antigen, these same PEC were not inhibited in their migration by up to $3 \mathrm{mg}$ of PPD-I-RNA. Still, these experiments do not exclude the presence of minute amounts of antigenic material which may be sequestered in the active I-RNA preparations.

For these reasons, we turned to chemical techniques for detecting antigen in our I-RNA preparations. One such antigen system which lent itself to this problem is the low MW (486) chemically-defined antigen ARS-NAT. Approximately $15.4 \%$ of the ARS-NAT antigen consists of arsenic which is detectable in trace amounts by known chemical and instrumental methods. Thus, arsenic can serve as a chemical marker for the presence of antigen in I-RNA capable of transferring ARSNAT sensitivity. RNA extracts from ARS-NAT sensitive donors known to transfer sensitivity to the antigen were assessed for arsenic content by atomic absorption spectroscopy (AAS) ${ }^{17}$. This 
technique assays the arsenic directly, has a sensitivity greater than any biological or chemical assay, and since the sample is exhaustively incinerated at $2700^{\circ} \mathrm{C}$, 'buried antigen' cannot escape detection. AAS, with a sensitivity of $0.1 \mathrm{ng}$, failed to detect arsenic in $250 \mu \mathrm{g}$ to $10 \mathrm{mg}$ of ARS-NAT I-RNA. Therefore, if arsenic is associated with the I-RNA material, it could be present in an amount of no more than $5 \mathrm{pg}$ in $500 \mu \mathrm{g}$ of RNA, the amount of RNA usually used for transfer of immunity. This corresponds to less than $0.0000065 \%$ ARSNAT antigen in the RNA extract.

Although, such a low level of possible contamination is strong indication that only RNA is involved, $\mathrm{CrouCH}^{24}$ has stated that even this low level of possible contamination does not exclude the involvement of antigen, and has made the following calculations.

'Starting with $1 \mathrm{mg}$ of total RNA we then exclude ribosomal and t-RNA giving us $50 \mu \mathrm{g}$ of RNA. Estimates of the size of immune RNA, as determined by sucrose gradient sedimentation are on the order of $14-18 \mathrm{~S}$ or about 2,000 nucleotides. If we ascribe all $50 \mu \mathrm{g}$ of RNA as being immune RNA, the following calculation can be made:

$$
\begin{gathered}
\frac{50 \times 10^{-6} \mathrm{~g} \mathrm{RNA}}{2 \times 10^{3} \text { nucleotides } 0.320 \mathrm{~g} / \text { mole nucleotide }} \\
=7.81 \times 10^{-11} \text { moles immune RNA } \\
6.5 \times 10^{-8} \mathrm{~g} \text { ARS-NAT/g RNA }
\end{gathered}
$$

or

$$
\begin{gathered}
6.5 \times 10^{-8} \mathrm{mg} \text { ARS-NAT/mg RNA } \\
\frac{6.5 \times 10^{-11} \mathrm{~g} \text { ARS-NAT }}{486 \mathrm{~g} / \mathrm{mole} \text { ARS NAT }}=1.11 \times 10^{-13} \text { moles ARS NAT }
\end{gathered}
$$$$
\text { giving }
$$$$
\frac{11.1 \times 10^{-14} \text { moles ARS-NAT }}{7.81 \times 10^{-11} \text { moles immune RNA }}
$$

$$
=1.04 \times 10^{-3} \frac{\text { moles ARS-NAT }}{\text { moles immune RNA }}
$$

or 1 molecule of ARS-NAT per 1000 molecules of immune RNA

In our view, there are certain limitations to this calculation, since: (1) Not all molecules are I-RNA specific for ARS-NAT; (2) most RNA is degraded during incubation with cells and no selective uptake of message species has been reported; (3) the amount of ARS-NAT used in the calculations represents the maximum amount possible and would therefore give an overestimate of the amount of ARS-NAT possibly present. Thus, although the complete ab- sence of antigen contamination in I-RNA may be impossible to prove, we believe it is improbable that the activity of ARS-NAT-I-RNA is due to super-antigen species.

Clearly, the ability of I-RNA-treated lymphoid cells to respond to antigenic stimuli not specified by their genotype would argue strongly in favor of an informational role for I-RNA. That this is often the case is supported by evidence demonstrating the transfer of allotypic $^{25}$ and idiotypic ${ }^{26}$ immunoglobulin specificities in humoral systems and by the transfer of DNP-oligolysine reactivity to genetically nonresponder Strain-13 guinea pigs ${ }^{16}$. In one series of experiments, I-RNA from DNPoligolysine immunized responder strain-2 guinea pigs was found to confer antigenically-specific reactivity on nonresponder Strain-13 guinea pig PEC as assessed by the MIF assay. These findings indicate that Immune-RNA-mediated transfers of cell mediated immunity can overcome an inherent genetic defect.

Indeed, if I-RNA does function as a vehicle for the transfer of genetically-specified immune reactivity, it is possible that a messenger RNA species might be responsible for this activity. Several lines of evidence are compatible with the possibility that the transfer activity of I-RNA is due to mRNA species. Estimates of the molecular size of the RNA species with transfer activity were first studied by THOR and DRAY $^{2}$ who reported the transfer of PPD reactivity with the 8-12S fraction of a preparation of human I-RNA obtained from lymph nodes of a PPD-sensitive donor (Fig. 3). Transfer activity of the separated 8-12 S RNA species was unaffected by DNase or trypsin but was abolished by RNase treatment. These findings were extended to a monkey I-RNA system by PAQUE and DRAY ${ }^{22}$ who showed that transfer activity was confined to the RNA species located between the $4 \mathrm{~S}$ and $18 \mathrm{~S}$ regions of a $5-20 \%$ linear sucrose density gradient. Subsequently, the size of the I-RNA species active in transferring anti-tumor reactivity in the guinea pig Line-10 hepatoma system was estimated to be $5-12 \mathrm{~S}^{27}$. These values are well within the range of the size of mRNA species determined in other systems. These data alone, however, do not discount a possible contribution by superantigen RNA moieties since the molecular size of such molecules is also within this range ${ }^{23}$. 
Another line of evidence which supports the idea that the transfer activity of I-RNA might be due to a messenger RNA species is the finding that transfer activity is associated with fractions of I-RNA having polyadenylic acid sequences characteristic of mRNA. Thus, Paque $^{28}$ and Paque and Nealon ${ }^{29}$ have reported the transfer of PPD, KLH, and ARSNAT sensitivity to nonsensitive guinea pig PEC as assessed by the MIF assay with Poly-A containing I-RNA from hyperimmune donors. The amount of Poly-A containing I-RNA needed for transfer was approximately 10 fold less than the amount of whole I-RNA extracts required. Furthermore, the transfer activity of Poly-A containing I-RNA exhibited the same degree of specificity for the sensitizing antigen as was seen for whole I-RNA preparations.

One difficulty in elucidating the mechanism of transfer in a cell-mediated immune system is the lack of knowledge of the receptors responsible for antigen recognition and activation of $T$ lymphocytes. If an antibody-like molecule is indeed the receptor for antigen on the $\mathrm{T}$ cell, the size of the RNA species with transfer activity is sufficient to code for a light chain or idiotypic specificities but not for a complete immunoglobulin molecule. Other receptors dissimilar to antibodies have also been suggested, however, so that speculation as to the amount of RNA needed to code for a portion of a receptor sufficient to designate antigen-specific recognition is tenuous at best. It is conceivable that the transfer of antigen-specific recognition to an unsensitized cell that is genetically capable of a response could occur by derepression of the host genome. The results of this event presumably would lead to the expression of genes encoding membrane receptors for antigen and to cellular activation upon subsequent antigenic challenge.

\section{Transfer of cell-mediated reactivity to tumor antigens.}

The successful transfer of delayed type hypersensitivity skin test reactivity to various nontumor antigens suggested that RNA extracts might also transfer cellular sensitivity to tumor antigens thereby exerting some potentially beneficial anti-tumor effects. These investigations utilized 2 antigenically distinct, chemically- induced transplantable guinea pig hepatomas, Ln-1 and Ln-10 and a syngeneic, transplantable murine plasmacytoma, MOPC-315. As a first step, the MIF assay was used to demonstrate I-RNA mediated transfer of tumor antigen specific reactivity to nonsensitive Strain-2 guinea pig $\mathrm{PEC}^{30}$. Strain-2 guinea pigs hyperimmunized to either tumor by the methods of ChURChILl et al. $^{31}$ and ZBAR et al ${ }^{32,33}$ served as sources of I-RNA and soluble tumor antigens were prepared using the $3 \mathrm{M} \mathrm{KCl}$ extraction procedures of REISFELD and KAHAN ${ }^{12}$ and MELTZER et $a l^{13}$. PEC incubated with Ln-10 I-RNA were specifically inhibited in their migration when stimulated with $\mathrm{Ln}-10$ tumor antigen but not with Ln-1 tumor antigen while the reverse was true using PEC incubated with Ln-1 IRNA. Controls which did not demonstrate inhibition of migration in the presence of tumor antigen included PEC incubated with RNA from kidney, muscle, and liver of Ln-10 immune animals as well as RNA prepared from the spleens of nonsensitive animals. The localization of the RNA fraction with transfer for Ln-1 and Ln-10 tumor antigen reactivity was also investigated and found in a fraction corresponding to a 5-12 $\mathrm{s} \mathrm{mw} \mathrm{species}{ }^{27}$. Fractions of $4 \mathrm{~s}, 18 \mathrm{~s}, 22 \mathrm{~s}$, and $28 \mathrm{~s} \mathrm{mw}$ did not exhibit transfer activity. These experiments served as an in vitro model for the development of tumor specific, anti-tumor reactivity in syngeneic lymphoid cells that potentially was applicable to in vivo immunotherapy. An in vivo immunotherapy model employing I-RNA from Ln-10 immune guinea pigs was then developed by SCHLAGER et al. ${ }^{35}$ subsequent to the aformentioned studies.

When $1 \times 10^{6} \mathrm{Ln}-10$ tumor cells are injected intradermally into Strain-2 guinea pigs, the tumor is uniformally lethal in 60-90 days with frequent metastases developing in the regional lymph nodes by the sixth day ${ }^{33}$. MIF, blastogenic, and delayed-type hypersensitivity skin test reactivity to soluble tumor associated antigens is reportedly detectable in tumor-bearing guinea pigs between 15 and 30 days following tumor injection ${ }^{34}$. Guinea pigs injected intradermally with $1 \times 10^{6} \mathrm{Ln}-10$ cells admixed with $6 \times 10^{6}$ living BCG bacilli rarely develop an established tumor, are resistant to subsequent challenge with tumor cells, and exhibit detectable skin test and MIF reactivity upon challenge 
with tumor cells or extracted tumor antigens ${ }^{13,30}$. When BCG is injected intratumorally 6 or 12 days following the injection of $1 \times 10^{6}$ Ln-10 cells, complete tumor regression is observed in approximately $85 \%$ and $20 \%$ of the animals respectively ${ }^{33}$. This tumor system provided a syngeneic tumor model suitable for testing a variety of immunotherapeutic procedures based on the transfer of Ln-10 immunity with I-RNA.

SCHLAGER et al. succeeded in developing an RNA therapeutic regimen which cured all guinea pigs bearing a uniformly lethal 5 to 7 day tumor transplant of Ln-10 hepatoma cells ${ }^{35-37}$. In this procedure, $1 \times 10^{7}$ syngeneic St-2 nonsensitive PEC (NS-PEC) were injected first into the area under the palpable tumor nodule followed immediately by $2.5 \mathrm{mg}$ of RNA from the lymphoid cells of either syngeneic (Syn) Ln-10 immune guinea pigs or xenogeneic (Xen), Ln-10 immune Rhesus monkeys. Approximately 1 hour later, $1.0 \mathrm{mg}$ of a biologically active preparation of extracted Ln10 tumor antigen (TSAg) was injected into the same inoculation site. In the first experiment, groups of 4 animals were used. In animals receiving the complete therapeutic regimen on NSPEC, Ln-10 I-RNA, and Ln-10 tumor antigens, complete local tumor regression was observed within 60 days after the injection of tumor cells. On the other hand, the control guinea pigs injected with $0.5 \mathrm{ml}$ saline under the tumor nodules exhibited progressive tumor growth to a maximum of $30 \times 30 \mathrm{~mm}$ and all animals died within 72 days $^{35}$. No effect on the developing neoplasm was observed when NSPEC or $2.5 \mathrm{mg}$ line-10 Syn-I-RNA were each injected alone or when NS-PEC were injected together with $2.0 \mathrm{mg}$ of bacterial RNA or with $1.0 \mathrm{mg}$ of line-10 TSAg. However, when $1 \times$ $10^{7}$ NS-PEC were injected together with $2.5 \mathrm{mg}$ line-10 Syn-I-RNA without TSAg, a significant decrease in the tumor growth progression was noted but the effect was transient and the animals all died within 102 days.

To extend these results, a second experiment was done with groups of 10 animals (Fig. 4). As before, when $1 \times 10^{7} \mathrm{NS}-\mathrm{PEC}, 2.5 \mathrm{mg}$ line-10 Syn-I-RNA, and $1.0 \mathrm{mg}$ line-10 TSAg $1 \mathrm{hr}$ later were injected s.c., complete local tumor regression was observed in 10 animals which were still alive and free of palpable tumors 120 days after tumor injection. In addition, almost identical results were obtained in 10 animals receiving $2.5 \mathrm{mg}$ line-10 Xen-I-RNA from Rhesus monkeys immunized to line-10 tumor cells instead of syngeneic RNA. Again, those control guinea pigs receiving saline 5 days after the tumor cell inoculum exhibited progressive tumor growth and all 10 animals died within 60-90 days, the interval in which $100 \%$ mortality due to the i.d. injection of $1 \times 10^{6}$ line-10 tumor cells is known to occur. Treatment with $1 \times 10^{7} \mathrm{NS}$ $\mathrm{PEC}$ alone or NS-PEC given with $1.0 \mathrm{mg}$ line-10 TSAg were ineffective against tumor growth and did not extend the survival time of the animals. When the injection of $1 \times 10^{7}$ NS-PEC was followed with $2.5 \mathrm{mg}$ of RNA from strain-2 guinea pigs immunized to the antigenically non-cross-reacting line- 1 tumor and $1.0 \mathrm{mg}$ line- $1 \mathrm{TSAg} 60 \mathrm{~min}$ later, no antitumor action was observed.

Although the combinations of nonsensitive guinea pig PEC, Ln-1 I-RNA, and line-1 TSAg was shown to elaborate migration inhibitory factor (MIF) in the in vitro assay, this regimen used in vivo demonstrated no therapeutic effect against the line-10 tumor. This suggests that MIF production alone is not sufficient for the

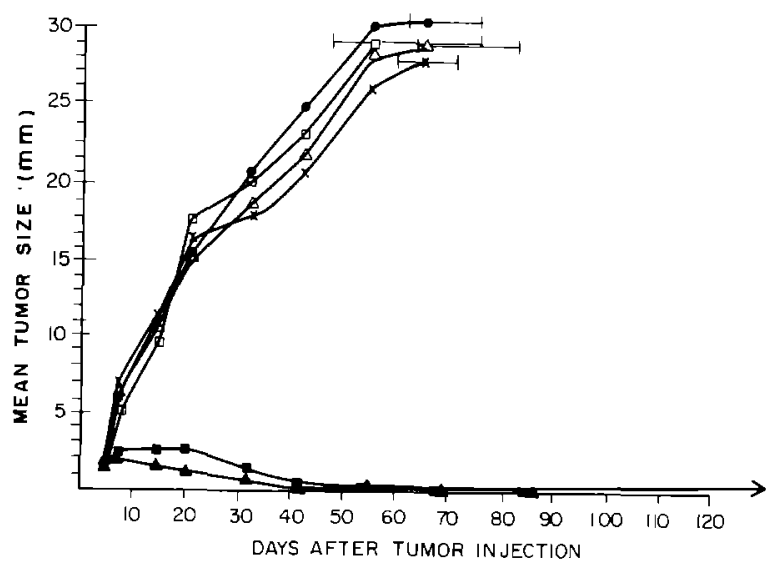

Fig. 4. Growth and development of $1 \times 10^{6}$ line 10 tumor cells in response to various therapeutic regimens including: $x$, strain 2 NS-PEC alone; $\square$, NS-PEC and line 10 TSAg; $\triangle$, NS-PEC, RNA from line 1 -immune strain 2 guinea pigs and line $1 \mathrm{TSAg}$;, NS-PEC, RNA from line 10-immune strain 2 guinea pigs and line $10 \mathrm{TSAg}$ - NS-PEC, RNA from line 10-immune Rhesus monkeys and line $10 \mathrm{TSAg}$; , tumor cells alone $(0.9 \% \mathrm{NaCl}$ solution therapy controls). Brackets indicate time interval in which all of the animals in that group died. Values represent average of 10 animals. (From Schlager and Dray ${ }^{35}$. Reproduced by permission of Cancer Research) 
regression of a growing neoplasm, although it is possible that an antigen-specific cytotoxic factor might be necessary to effect an anti-tumor response. Along these lines, VeLTMAN et al. ${ }^{38}$ demonstrated that xenogeneic RNA obtained from guinea pigs or sheep immunized to a human tumor and incubated with normal human lymphocytes in vitro could transfer anti-tumor cytolytic activity to the lymphocytes. They suggest that the RNA acted to "convert" the normal human lymphocytes into "killer cells" and that MIF production was not necessarily the essential factor involved in the cytolysis of the tumor cells. Furthermore, although the use of xenogeneic RNA makes the determination of the specificity of the anti-tumor response more difficult, RAMming and PILCH ${ }^{39}$ provided convincing evidence that when xenogeneic 'tumorimmune' RNA is incubated with lymphoid cells that are syngeneic with the tumor cells, only tumor-specific immune responses are transferred.

The original RNA therapy model developed in the Ln-10 hepatoma system was extended to include treatment of guinea pigs with later stage tumors and treatment of guinea pigs with tumors at two distinct sites ${ }^{36,37}$. In these experiments, complete tumor regression was achieved in animals that had received a single intradermal injection of $1 \times 10^{6}$ Line- 10 cells ( 5 or 7 days previously) by the subcutaneous injection of Line-10 Immune-RNA, $1 \times 10^{7}$ nonsensitive Strain-2 PEC, and $1 \mathrm{mg}$ of Line-10 tumor specific antigen under the site of the tumor nodule. If either the nonsensitive PEC, the I-RNA, or the Line-10 antigen was deleted from the regimen, or if treatment was delayed until day 12,17 or 21 of tumor growth, the animals were not cured and their survival was not prolonged. In another experiment, it was found that treatment of one tumor nodule with the complete immunotherapeutic regimen 5 days after tumor inoculation cured not only the treated primary nodule but a second, untreated nodule ( $10 \mathrm{cms}$ apart from the primary nodule) also completely regressed. These data indicate that the results of immunotherapy with the complete regimen is effective in eliciting systemic anti-tumor immunity of sufficient magnitude to cure guinea pigs with a single otherwise lethal tumor that has grown for 7 days or two tumors that have grown for 5 days.
The limitations of this therapeutic regimen have yet to be completely defined due to the technical difficulties inherent in preparing IRNA and tumor antigen extracts with quantitatively reproducible biological activity. Also, the limited availability of male Strain-2 guinea pigs and the unavailability of a uniformly lethal syngeneic tumor as a specificity control have hampered the effort to extend the exploration of additional RNA therapy models in the Ln-10 tumor system. These reasons, coupled with the desire to extend the RNA therapy approach to other tumor systems led to investigations into a syngeneic murine tumor system, the MOPC-315 plasmacytoma.

MOPC-315 plasmacytoma was originally developed by the intraperitoneal injection of mineral oil in $\mathrm{BALB} / \mathrm{c}$ mice $^{40}$. The tumor is characterized by its ability to secrete monoclonal IgA immunoglobulins with reactivity for DNP haptenic groups. When BALB/c mice are inoculated subcutaneously with $1 \times 10^{6} \mathrm{MOPC}$ 315 tumor cells, progressive tumor growth develops which kills the mice in $17 \pm 2$ days. It was found that mice inoculated with this dose of tumor cells mounted a transient anti-tumor response that was detectable in vitro in their PEC by MIF testing with soluble tumor antigens early (5-7 days post tumor grafting) during tumor development ${ }^{41}$. PEC from mice with later stage tumors (10-14 day post tumor grafting) did not respond to extracted MOPC-315 antigens by MIF production. Preliminary experiments to elucidate the mechanism responsible for the loss of tumor antigen reactivity in PEC from mice with late stage tumors implicated a possible depressive role for serum factors ${ }^{42,43}$, suppressor lymphocytes ${ }^{43}$ or suppressor macrophages $^{44}$.

Next, we investigated whether I-RNA with tumor antigen transfer activity could be extracted from the spleens of tumor-bearing mice at any stage of tumor development ${ }^{41}$ (Fig. 5). It was found that I-RNA prepared from the spleens of mice bearing early stage tumors (5-6 days post-tumor grafting) was able to transfer MOPC-315 tumor antigen responsiveness to nonsensitive BALB/c PEC. However, I-RNA prepared from the spleens of mice bearing later stage tumors (12-14 days post-tumor grafting) was unable to transfer tumor antigen responsiveness to nonsensitive PEC. It appeared 


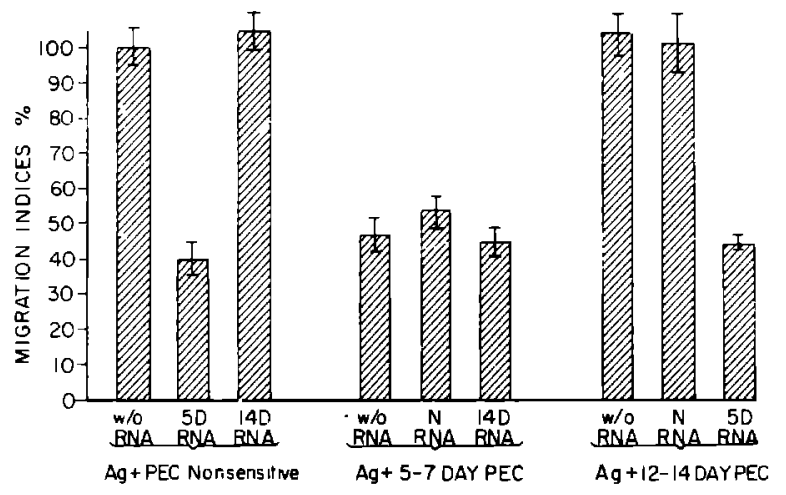

Fig. 5. (From Braun and DraY ${ }^{41}$. Reproduced by permission of Cancer Research). Effect of normal RNA or RNA from MOPC-315-bearing animals on the migration of PEC obtained from normal or tumor-bearing mice in the presence or absence of antigenic stimulation with MOPC-315 TAAg. N RNA, RNA from normal BALB/c mice. 5 D RNA, RNA from mice grafted 5 or 6 days previously with $1 \times 10^{6}$ MOPC-315 tumor cells. 14 D RNA, RNA from mice grafted 12 to 14 days previously with $1 \times 10^{6}$ MOPC315 cells. Bars, E.E.

therefore that the ability to extract I-RNA with transfer activity for tumor antigen responsiveness was correlated temporally with the ability of the PEC from the tumor-bearing I-RNA donors to respond to tumor antigen stimulation. Since the PEC from mice that had borne the MOPC-315 tumor for 14 days were incapable of responding to tumor antigen we next performed experiments to determine if the I-RNA from 5-6 day tumor-bearing mice, that had exhibited tumor antigen transfer tumor activity when tested with nonsensitive PEC, could also transfer tumor antigen responsiveness to the unresponsive, day 14 tumor-bearer PEC. When PEC from mice bearing late stage MOPC-315 tumors were incubated with $200-500 \mu \mathrm{g}$ of I-RNA prepared from the spleens of mice with early stage tumors, inhibition of migration was observed in cultures of RNA-treated cells that had been stimulated with MOPC-315 tumor antigens but not in cultures of RNA-treated cells stimulated with MOPC-104E tumor antigens. Cells that had not been treated with RNA from early stage tumor-bearers or cells that had been treated with RNA from normal mice were not inhibited in their migration in the presence of biologically active MOPC-315 tumor antigen.

The observed inability to prepare I-RNA with MOPC-315 tumor antigen transfer activity from spleens of mice with late stage tumors indicated that cells containing biologically active I-RNA were lacking in the late stage tumor-bearer spleen cells. This phenomenon was investigated further by immunizing MOPC-315 tumorbearing mice with $\mathrm{BCG}$ on the second day of tumor growth and subsequently preparing IRNA from the tumor-bearer spleens on the 14 th day of tumor growth ${ }^{41}$. This preparation was used to treat nonsensitive mouse PEC which were then incubated in the presence of MOPC-315 tumor antigens or PPD. In these experiments, RNA-treated cells exhibited inhibition of migration in the presence of PPD but not in the presence of MOPC-315 tumor antigen indicating that the lack of MOPC-315 transfer activity in I-RNA from spleens of late stage tumor-bearers was not due to a generalized depression of host I-RNA synthesis. We also demonstrated that the late stage IRNA which did not exhibit tumor antigen transfer activity to nonsensitive PEC was incapable of preventing MIF production by tumor antigen-responsive PEC from mice bearing early stage (5-7 day) tumors. This series of experiments in the MOPC-315 tumor system suggested that the synthesis of I-RNA with transfer activity for tumor antigen declines during tumor growth.

\section{Discussion}

The transfer of cell-mediated immunity via I-RNA is subject to a variety of technical difficulties. Certain of these difficulties pertain to cellular reactivity in general and are due to an incomplete delineation of the reaction mechanisms involved and the cell populations participating in the development and expression of cell-mediated immunity. These difficulties are compounded by the lack of quantitatively reproducible assays for measuring cell-mediated reactivity. But aside from these considerations, RNA transfers suffer some unique problems which can lead to difficulties in reproducing certain phenomena. In our experience, most failures in attempting I-RNA-mediated transfer of cellular immunity are due to the following: (1) the donor lymphoid cells may not contain a sufficient amount of I-RNA; (2) the I-RNA preparations are degraded or are toxic to the cells; (3) the antigens used to stimulate I-RNAtreated cells, particularly in tumor antigen systems, are not active since they are poorly 
defined, impure and have not been quantitated. The future application of I-RNA to the study of cell biology and particularly to the therapy of human disease states might well depend on the ability to deal with these problems.

RNA transfer methodology entails immunization of donors, extraction of I-RNA, incubation of I-RNA with recipient cells, and assessment of transfer activity by in vivo and in vitro tests. Consideration of some of these procedures is relevant to any discussion of the problems associated with, and the future of, I-RNA mediated transfer of cellular immunity.

The immunization of animals serving as donors of I-RNA is aimed at eliciting a hypersensitive state in the donor. It has been repeatedly observed that animals with marginal or weak reactivity to antigenic challenge are poor donors of I-RNA. It was also observed in the MOPC-315 plasmacytoma system that the ability of tumor-bearing mice to provide I-RNA with transfer activity for tumor antigen responsiveness is restricted to the early stage of lethal tumor growth which is characterized by host PEC responsiveness to tumor antigens. These observations suggest that the level of I-RNA synthesis that occurs in donor lymphoid cells is correlated with the degree of sensitivity possessed by the donor. If it can be assumed that the amount of I-RNA contained in the donor lymphoid tissue is correlated with the number of antigen sensitive cells in the tissue, then the inability of marginally sensitized animals or terminal, unresponsive plasmacytoma-bearing mice to serve as good sources of I-RNA probably reflects an insufficiency in the number of antigen sensitive cells in these hosts. This consideration raises the question of which cell type(s) are able to synthesize I-RNA. Early studies by ADLER et al. ${ }^{45}$ and Fishman and ADLER $^{46}$ indicated that macrophage derived RNA was able to transfer antibody synthesizing ability to lymphocytes. These reports suggested that the macrophage RNA might function as a modulator of lymphocyte responsiveness capable of signaling either antibody synthesis or lymphokine production upon antigenic challenge. Furthermore, WANG and MANNICK have presented evidence that macrophage RNA has transfer activity for anti-tumor cytotoxic responses in a murine tumor system ${ }^{47}$. In contrast, KERN et al. have reported that I-RNA with transfer activity for anti-tumor cytotoxicity is synthesized by the $\mathrm{T}$ lymphocyte ${ }^{48}$. In this study, both the cell synthesizing I-RNA and the cell which apparently incorporated the I-RNA was the $\mathrm{T}$ lymphocyte. It becomes apparent that there is considerable controversy concerning the nature of the cells involved in synthesizing I-RNA. Still, the identification of the I-RNA producing cell type(s) would aid greatly in attempts to enrich the activity of I-RNA. On the assumption that the number of cells with antigen reactivity even in a hypersensitized population is relatively small, one enrichment approach that might be exploited is the expansion of the I-RNA-producing cells either by cloning techniques or by the recently developed hybridoma technique. Hybridomas consisting of murine plasmcytoma cells and lymphocytes have been produced in several laboratories ${ }^{49-51}$. Immune spleen cells are first cloned and clones of immune cells within the population identified. These clones are then hybridized by glutyraldehyde with murine myeloma cells selected for their inability to secrete myeloma proteins. The hybrid cells exhibit the immune function of the selected lymphocytes specified by the immunized donor and can be propagated continuously either in tissue culture or as hybridoma tumors in mice. If this technology can be applied to obtain hybridomas synthesizing IRNA, it would represent a significant advancement in the technology for obtaining large quantities of relatively pure and biologically active I-RNA.

A variety of methods have been employed for preparing biologically active I-RNA. In our own experience, the hot/cold phenol method has been the most successful since the material recovered is usually undegraded and of low viscosity which facilitates its incubation with cells. Further enrichment of transfer activity by fractionation of the extracted material has also been accomplished with hot/cold phenol preparations of I-RNA. Paque and coworkers have utilized 2 different approaches to enrich the transfer activity of hot/cold extracted preparations. One method utilizes sucrose density gradient fractionation of the starting material to obtain the 5-18 s molecular weight species in the preparation ${ }^{27}$. Most or all of the transfer activity contained in the initial preparation was localized to this fraction. Another approach at 
enrichment by fractionation is the isolation of poly-A-containing RNA species in the I-RNA preparation by oligo-dt-column chromatography $^{28,29}$. Both of these methods led to a 10-100 fold enrichment of transfer activity. Still, it is not yet clear whether transfer activity reflects the activity of a single species or of multiple species of RNA moieties. The controversy over the activity of superantigen containing I-RNAs and/or informational I-RNAs reflects this issue since both types of molecules have been identified in I-RNA. Moreover, certain investigations have illustrated biological roles for RNA moieties other than transfer activity which might effect the outcome of attempted transfer with I-RNA. One such activity that has been explored is the adjuvant-like properties of RNA moieties. Synthetic homopolymers of oligoribonucleotides have been used to augment the antibody-forming capacities of aged mice ${ }^{52}$. In addition, there are reports showing that both whole cell RNA and ribosomal RNA species are effective in inducing resistance in mice against a challenge with virulent strains of the bacterial species used to prepare the RNA ${ }^{53}$. This kind of activity appears to operate nonspecifically on the cellmediated immunity system since in this study, it was shown that mice injected with either Toxoplasma gondii derived RNA, normal peritoneal macrophage RNA, or synthetic polyribonucleotides were resistent to challenge with Toxoplasma gondii, an organism known to be sensitive to cell-mediated immunity. The activity of these RNA moieties was sensitive to RNase but not pronase and the mechanism responsible for the activity was attributed to nonspecific activation of macrophages. The induction of immunological depression is another phenomena that has been accomplished with RNA. Heller et al ${ }^{54}$, Bhoopalam et al..$^{55}$ and KATZMANN et al. ${ }^{56}$ have demonstrated depression of the primary immune response in mice injected with plasmacytoma RNA. The depression observed was attributed to the ability of plasmacytoma RNA to convert normal B lymphocytes to bear on their surface the monoclonal immunoglobulins specified by the tumor. In a separate system, administration of normal liver or spleen RNA from BALB/c mice 1 or 5 days prior to antigen injection depressed host responsiveness to a syngeneic leukemia, lym- phocyte responsiveness to PHA, and antibody formation to sheep erythrocytes ${ }^{57}$. The immunodepressive activity was attributed to actions exerted both on macrophages and lymphocytes and was abolished by treatment of the RNA with RNase. These additional activities of RNA could conceivably effect the transfer activity of I-RNA. Indeed, a successful transfer of cell-mediated immunity with I-RNA might reflect the participation of all of these moieties. Whether these effects represent the actions of distinct RNA species or multiple activities of a single species is presently unclear. What is clear, however, is the need to pursue further investigations into the biological effects of I-RNA so that methods can be developed to isolate the most potent combinations of materials.

The incubation of lymphoid cells with I-RNA is a crucial step in the transfer of biological activity and is often fraught with technical difficulties. Predominant among these is the extreme sensitivity of I-RNA to ribonucleases which appear to be ubiquitous to most biological systems. Any RNA transfer, be it in vitro or in vivo, must attempt to deal with the problem of ribonucleases. Most attempts have centered upon inhibiting the activity of these enzymes with sodium dextran sulphate or polyvinyl sulphate. The success of this approach, particularly for RNA injected in vivo is questionable since Enesco found that intravenously injected $\mathrm{C}^{14}$ labeled RNA is rapidly broken down to free bases and ribose, the bases contributing to the free nucleotide pool and the ribose fraction being utilized in carbohydrate metabolism or exhaled as $\mathrm{CO}_{2}{ }^{58}$. Another aspect of this problem is the limited capacity of cells to incorporate biologically active I-RNA. This difficulty may be a manifestation of both the influence of ribonucleases in the incubation environment as well as the competence of the cells to take up the I-RNA. Several lines of evidence suggest that the ability of cells to incorporate I-RNA is subject to biological restrictions. First, it is usually observed that cells incubated with I-RNA do not express the transferred activity unless they are subsequently stimulated with the immunizing antigen. This has been interpreted to indicate that the number of cells which are actually converted to antigenic sensitivity by I-RNA is relatively small. This was seen by Schlager et al. in the 
Line-10 heptoma system who observed that guinea pigs treated with I-RNA and syngeneic nonsensitive PEC alone exhibited weak antitumor reactivity whereas the addition of extracted tumor antigens to the therapy regimen resulted in complete tumor regression ${ }^{35}$. Apparently, the additional stimulation of converted cells by antigen led to the expansion of the antigen reactive cells to a level sufficient to cause tumor regression. In this study, however, the participation of additional host cells might also have been responsible for the differences seen in the presence or absence of antigen.

Aside from the observations suggesting that only a limited number of cells are actually converted by I-RNA, the tacit assumption that lymphoid cells can incorporate I-RNA has only rarely been tested. To directly test this assumption, Wang et al. studied the fate of the I-RNA incorporated by rabbit lymphoid cells and found that rabbit spleen cells can incorporate a small but measurable amount of radioactively-labeled rabbit lymph node RNA ${ }^{59}$. Approximately $4 \times$ $10^{10}$ daltons of RNA which was demonstrably resistant to RNase was incorporated per cell at saturation, representing approximately $0.2 \%$ of the amount of input RNA used. The RNA incorporated was found in all 3 subcellular fractions analyzed and had a nucleotide composition similar to that of the input RNA. Interestingly, the amount of bacterial RNA incorporated by rabbit spleen cells was substantially lower than the level of rabbit RNA incorporated and was rapidly degraded intracellulary. Also, it was found that nonincorporated RNA was rapidly and completely degraded, presumably by cell-associated nucleases, within the first 15 minutes of incubation ${ }^{60}$. With all of these considerations in mind, it becomes difficult to envision how, under such circumstances, a precise amount of RNA molecules can be delivered into the proper recipient cells in a reproducible manner. Thus, the ability of cells to incorporate I-RNA is subject to several severe restrictions and may well be the limiting factor which determines the success or failure of the transfer of biological activity.

Several procedures have been employed to facilitate the cellular incorporation of administered RNA, with the most utilized being the microinjection of specific messages into Xenopus oocytes $^{61}$. In this instance the production of a message-specific translation product has been reported. However, since the frog oocyte is an undifferentiated cell, data obtained in this system may not accurately reflect processes in differentiated eukaryotic cells. GraESSMANN $e t$ $a l^{62}$ have overcome this problem by the microinjection of RNA into differentiated eukaryotic cells. However, this method is not practical for studies requiring the administration of messenger RNA to a large number of cultured cells. A preliminary report by ANDERSON and KRUEGER $^{63}$ has been published which documents the development of a technique which entails the encapsulation of globin mRNA within erythrocyte ghosts and the transfer of the sequestered message into hamster cells by the addition of sendai virus. While this procedure may facilitate the transfer of message to cultured cells, the addition of a viral fusogen virtually eliminates any potential clinical application.

The dual problem of the protection of RNA from ribonuclease degradation and the insertion of RNA into a large number of cells without the addition of a viral fusogen may be resolved by the sequestration of RNA within liposomes. In order to utilize lipsomes as a vehicle for transporting messenger RNA into cells, two criteria must be fulfilled: (1) the liposomal aqueous space must be of sufficient volume so as to allow the sequestration of large numbers of molecules of very high molecular weight, (2) the structure of the liposomes must permit the efficient transfer of the sequestered RNA into the cytoplasm of the recipient cell. The latter condition would require the utilization of unilamellar vesicles since all but the contents of the outermost aqueous space of multilamellar vesicles would be processed by the lysosomal apparatus $^{64}$.

DeAmer and BAngham ${ }^{65}$ have devised a technique for the production of large unilamellar liposomes ( $1 \mu$ diameter) by ether infusion. Ostro et al. have employed this technique to sequester high molecular weight RNA (4 S to $23 \mathrm{~S}$ ) within liposomes and have demonstrated that the encapsulated RNA is resistant to external ribonuclease degradation ${ }^{66}$.

In a subsequent report ${ }^{67}$, it was demonstrated that cells treated with liposomally encapsulated globin mRNA are stimulated to produce a globin-like protein. Application of a similar 
approach by MAGEE et al. ${ }^{68}$ to the guinea pig Ln-10 hepatoma tumor system led to a marked stimulation of lymphocyte-mediated attack on tumor cells that was up to 12 times greater than the activity seen with naked I-RNA.

In our view, the goal of any future studies concerning I-RNA should focus, at least in part, on developing better methods to (1) obtain active I-RNA; (2) incorporate I-RNA into cells; (3) quantitiate the activity of I-RNA-treated cells. In terms of I-RNA procurement, a knowledge of the cell type(s) which synthesize I-RNA, coupled with methods to expand the I-RNA producing cell population, would greatly facilitate the isolation and characterization of the most active I-RNA moieties. The ability to incorporate large amounts of biologically active I-RNA into cells through the use of liposomes or other vehicles would allow for better defined experiments which are more reproducible. The development of a more precise means of assessing the biological activities of I-RNA would permit a rational study of the molecular mechanism(s) responsible for I-RNA-mediated immunological transfer. With improved I-RNA technology, it should become possible to modulate the immune responsiveness of lymphoid cells in a predictable manner for application to a variety of problems in both basic and clinical sciences.

\section{References}

1. Scherrer, K. and Darnell, J. E., 1962. Biochem. Biophys. Res. Commun. 7, 486-490.

2. Thor, D. E. and Dray, S., 1968. J. Immunol. 101, 469-480.

3. Paque, R. E. and Dray, S., 1970. J. Immunol. 105, 1334-1338.

4. Paque, R. E., 1978. In Methods in Cancer Research (Busch, H., editor) v15, 279-343, Academic Press, Inc. New York.

5. George, M., Vaughn, J. H., 1962. Proc. Soc. Exp. Biol. 111, 514-521.

6. Harrington, J. T. and Stastny, P., 1973. J. Immunol 110, 752-759.

7. Jureziz, R. E., Thor, D. E. and Dray, S., 1968. J. Immunol. 101, 823-829.

8. Bergstrand, H. and Kallen, B., 1973. Scand. J. of Immun. 2, 173-187.

9. Thor, D. E., Jureziz, R. E., Veach, S. R., Miller, E. and Dray, S., 1968. Nature 219, 755.

10. Mortensen, R. F., Braun, D. and Gewurz, H., 1977. Cell Immunol. 28, 59-68.
11. Vithayasai, Vicharn, 1972. Ph. D. Thesis, University of Illinois at the Medical Center.

12. Reisfeld, R. A. and Kahan, B. D., 1970. Fed. Proc. 29, 2034.

13. Meltzer, M. S., Leonard, E. J., Rapp, H. J. and Borsos, T., 1971. J. Natl. Cancer Inst. 47, 703-709.

14. Thor, D. E., 1967. Science 157, 1567-1569.

15. Thor, D. E. and Dray, S., 1973. Ann. N.Y. Acad. Sci. 207, 369-379.

16. Paque, R. E., Ali, M. and Dray, S., 1975. Cell. Immunol. 16, 261-268.

17. Schlager, S. I., Dray, S. and Paque, R. E., 1974. Cell. Immunol. 14, 104-122.

18. Jureziz, R. E., Thor, D. E. and Dray, S., 1970. J. Immunol. 105, 1313-1321.

19. Paque, R. E. and Dray, S., 1970. J. Immunol. 105, 1334-1338.

20. Paque, R. E. and Dray, S., 1972, Cell. Immunol. 5, 30-41.

21. Paque, R. E. and Dray, S., 1973. Ann. N.Y. Acad. Sci. 207, 369-379.

22. Paque, R. E. and Dray, S., 1974. Transpl. Proc. 6, 203-207.

23. Gottlieb, A. and Schwartz, R. H., 1972. Cell Immunol. 5, 341-362.

24. Crouch, R. J., 1976. In Immune RNA in Neoplasia (Fink, Mary E., editor), pp. xvi, Academic Press Inc., New York.

25. Bell, C. and Dray, S., 1969. J. Immunol. 103, 11961211.

26. Giacomoni, D., Yakulis, V., Wang, S. R., Cooke, A., Dray, S. and Heller, P., 1974. Cell. Immunol. 11, 380-400.

27. Paque, R. E., (1976) in Immune RNA in Neoplasia (Fink, Mary A., editor), pp. 235-244, Academic Press Inc., New York.

28. Paque, R. E., 1977. Cell. Immunol. 30, 332-340.

29. Paque, R. E. and Nealon, T., (1977). Cell. Immunol. 34, 279-288.

30. Paque, R. E., Meltzer, M. S., Zbar, B., Rapp, H. J. and Dray, S., 1973. Cancer Res. 33, 3165-3177.

31. Churchill, W., Rapp, H., Kronman, B., et al., 1968. J. Natl. Cancer Inst. 41, 13-29.

32. Zbar, B., Bernstein, I., Tanaka, T., et al., 1970. Science 170, 1217-1218.

33. Zbar, B., Bernstein, I. D., Barlett, G. L., Hanna, M. G. and Rapp, H. J., 1972. J. Natl. Cancer Inst. 49, 119-130.

34. Littman, B. H., Meltzer, M. S., Cleveland, R. P., Zbar, B. and Rapp, H. J., 1973. J. Natl. Cancer Inst. 51, 1627-1635.

35. Schlager, S. I., Paque, R. E. and Dray, S., 1975. Cancer Res. 35, 1907-1914.

36. Schlager, S. I. and Dray, S., 1975. Proc. Nat. Acad. Sci. USA $72,3680-3682$.

37. Schlager, S. I. and Dray, S., 1976. Israel J. Med. Sci. 12, 344-359.

38. Veltman, L. L., Kern, D. H. and Pilch, Y. H., 1974. Cell. Immunol. 13, 367-377.

39. Ramming, K. P. and Pilch, Y. H., 1971. J. Natl. Cancer Inst. 46, 735-750.

40. Potter, M., 1972. Physiol. Rev. 52, 639-719, 1972. 
41. Braun, D. P. and Dray, S., 1977. Cancer Res. 37, 4138-4144.

42. Kolb, J., Poupon, M. and Lespinats, G., 1974. J. Nat. Cancer Inst. 52, 723-727.

43. Braun, D. P. and Dray, S., 1976. Proc. Am. Assoc. Cancer Res. 17, 7.

44. Mokyr, M. B., Braun, D. P. and Dray, S. (in press) Cancer Res.

45. Adler, F. L., Fishman, M. and Dray, S., 1966. J. Immunol. 97. 554-558.

46. Fishman, M. and Adler, F. L., 1967. In Immunity, Cancer, and Chemotherapy (Mihich, E., editor), pp. 177-185, Academic Press, New York.

47. Wang, B. S., Onikul, S. R. and Mannick, J. A., 1978. Cell. Immunol. 39, 27-35.

48. Kern, D. H., Chow, N. and Pilch, Y. H., 1978. J. Natl. Cancer Inst. 60, 335-344.

49. Milstein, C. and Kohler, G., 1977. In Antibodies in Human Diagnosis and Therapy (Haber, E., and Krause, R. M., editors) pp. 271-284, Raven Press, New York.

50. Kohler, G. and Milstein, C., 1975. Nature, 256, 495-497.

51. Kontiainen, S. L., Simpson, E., Bohrer, E., Beverley, P. C. L., Herzenberg, L. A., Fitzpatrick, W. C., Vogt, P., Torano, A., McKenzie, I. R. C. and Feldman, M., 1978. Nature 274, 477-480.

52. Braun, W., Yajima, Y. and Ishizuka, M., 1970. J. Recticuloendothelial Soc. 7, 418-422.

53. Araujo, F. G. and Remington, J. S., 1974. Immunol. 27, 711-721.

54. Heller, P., Bhoopalam, N., Cabana, V., Costea, N. and Yakulis, V., 1973. Ann. N.Y. Acad. Sci. 207, 468-480.

55. Bhoopalam, N., Yakulis, V., Giacomoni, D. and Heller, P., 1976. Clin. Exp. Immunol. 23, 139-148.

56. Katzmann, J., Giacomoni, D., Yakulis, V. and Heller, P., 1975. Cell. Immunol. 18, 98-109.

57. Colmerauer, M. E. M., Rumi, L., Saal, R., Pasqualini, C. D. and Rabasa, S. L., 1973. J. Immunol. 111, 743-749.

58. Enesco, H. E., 1966. Exp. Cell. Res. 42, 640-645.

59. Wang, S. R., Giacomoni, D. and Dray, S., 1973. Exp. Cell. Res. 78, 15-24.

60. Giacomoni, D., Wang, S. R. and Dray, S., 1973. Ann. N.Y. Acad. Sci. 207, 251-257.

61. Lane, C. D., Marabaix, G. and Gurdon, J. B., 1971. J. Mol. Biol. 61, 73-91.

62. Graessmann, A., Graessmann, M. and Mueller, C., 1977. Proc. Natl. Acad. Sci. USA 74, 4831-4834.

63. Anderson, W. F. and Krueger, L. J., 1976. Cell. Biol. $70,185 a$.

64. Cohen, G. M., Weissmann, G., Hoffstein, S., Awasthi, Y. C. and Srivastava, S. K., 1976. Biochem. 15, 452-460.

65. Deamer, D. and Bangham, A. D., 1976. Biochim. Biophys. Acta. 443, 629-634.

66. Ostro, M. J., Giacomoni, D. and Dray, S., 1977. Biochem. Biophys Res. Commun. 76, 836-842.

67. Ostro, M. J., Giacomoni, D., Lavelle, D., Paxton, W. and Dray, S., 1978. Nature 274, 921-923.

68. Magee, W. E., Cronenberger, J. H. and Thor, D. E., 1978. Cancer Res. 38, 1173-1176. 